\title{
SPECIES CAPSIDARUM \\ QUAS LEGIT EXPEDITIO DANICA GALATEAE
}

DESCRIPSIT

O. M. REUTER. ${ }^{1}$

\section{Lygus (HahN) Reut.}

Gen. Cimic. Eur. p. 15.

L. bengalicus n. sp.: Virescens, subtiliter pallido-pubecens, capite, antennis, apicibus femorum, tibiis tarsisque magis minusve in sangvineo-brunneum vergentibus; apice clypei piceo; antennis saltem a tertia basali parte articuli secundi apicem versus fuscis, saepe maris etiam articulo secundo toto fusco; pronoto piceo, macula magna antica rotundata virescenti-livida $\left(\sigma^{\top}\right)$ vel sordide virescente, plagis duabus intramarginalibus latis interdum postice valde dilatatis et ante limbum basalem confluentibus, his signaturis autem interdum obsoletis ( $q$ ); hemielytris macula ad angulum interiorem apicalem corii fusca, membrana leviter fumata, areolis immaculatis vel apice areolae majoris dilute infuscato, stria hyalina ad apicem cunei $\left(\sigma^{7}\right)$ vel maculis duabus hyalinescentibus ante medium limbi externi (Q); tarsis apice nigro-fuscis; capite basi pronoti duplo angustiore, vertice maris lateribus fortius medio tenuius carinato-marginato, utrinque ante marginem transversim impresso, feminae toto omnium tenuissime marginato, margine verticis postico oculo aeque lato $\left(\sigma^{7}\right)$ vel hoc saltem dimidio latiore (O); oculis in genas longe extensis; rostro coxas

\footnotetext{
${ }^{1}$ Specimina typica in Museo Universitatis Havniensis asservantur.
} 
posticas attingente; antennis articulo secundo maris crassiusculo margini basali pronoti longitudine aequali vel hoc paullulum fere longiore, feminae hoc margine paullo breviore, ultimis simul sumtis secundo brevioribus; pronoto basi quam apice paullo magis quam duplo latiore, aequaliter sat dense punctato, callis parvis medio late distantibus; scutello levius transversim strigoso; hemielytris sat dense punctatis; tibiis tenuiter concoloriter spinulosis, anticis submuticis; terebra feminae medium ventris longe superante. Long. $\sigma^{7} 3 \frac{1}{2}$, $+4 \mathrm{~mm}$.

Patria: Bengalia, $3 \sigma^{7} \sigma^{7}, 4$ 9 .

L. obtusus n. 'sp.: Livido-virescens, sub-glaber, subtilissimepunctulatus, oculis fuscis, clypeo, loris, vitta pleurarum prothoracis, strictura apicali limboque basali pronoti medio, vitta media scutelli, clavo suturis omnibus (interioribus latius), corii macula apicali, margine apicali cunei (medio interrupte), arcu communi apicali areolarum maculisque duabus limbi externi membranae fuscis, altera paullo pone apicem cunei, altera pone medium posita; pedibus virescenti-lividis, innotatis, tibiis nigro-spinulosis, tarsis articulo ultimo versus apicem late nigro-fusco; capite brevi, verticali, clypeo parum prominente, subverticali, fronte ochraceostrigosa, vertice $\left(\sigma^{7}\right)$ oculo magno laevi latitudine aequali, postice crasse et obtuse marginato; rostro coxas intermedias attingente; antennis articulo secundo margini postico pronoti longitudine subaequali, saltem tertia apicali parte nigro; pronoti apice solum paullo et basi solum circiter $1 / 3$ angustiore, omnium subtilissime punctulato, callis sat obsoletis; scutello tenuissime transversim strigoso et parcius omnium subtilissime punctulato; hemielytris subtiliter punctatis, cuneo sub-laevi; terebra feminae medium ventris longe superante. Long. $\subsetneq 3 \frac{2}{3} \mathrm{~mm}$.

Patria: Bengalia; г $q$.

\section{Charagochilus FIEB.}

Eur. Hem. p. $27 \mathrm{I}$.

Ch. longicornis n. sp.: A Ch. Gyllenhali FaLl., cui magnitudine, colore, pubescentia et punctura maxime similis, differt solum antennis longioribus, tenuioribus aliterque coloratis, capite 
infra oculos longius producto, pronoto angustiore, scutello magis rugoso; antennis articulo primo nigro, secundo latitudini posticae pronoti longitudine subaeqvali $(q)$ vel hac paullo longiore $\left(\sigma^{7}\right)$, testacea, fere $2 / 5$ apicalibus nigro, tertio et quarto nigris, illo ipsa basi flavente, secundo duplo et quarto $1 / 4$ breviore; pronoto basi longitudine parum vel paullulum latiore. Long. $\sigma^{\top} 3^{2} / 5$, f $3 \% \mathrm{~mm}$.

Patria: insulae Nicobares, Terressa; 3 spp.

\section{Camptobrochis Fieb.}

Eur. Hem. p. 248.

C. parvulus Reut., Berl. Entom. Zeitschr. XXV (I88 I), p. I 58, 9; varietas: piceo-nigra, nitidula, solum capite stricturaque apicali pronoti obscurius rufo-testaceis, antennis pedibusque pallide flaventibus, apice articuli antennarum tertii quartoque toto nigris. Long. $\sigma^{7} 2 \frac{2}{5}$, $2_{2}^{1} \frac{\mathrm{mm}}{2}$

Patria: insula Madeira, S:ta Anna; I $\sigma^{7}$, I $q$.

\section{Halticus Fieb.}

Eur. Hern. p. $28 \mathrm{I}$.

H. minutus n. sp.: Niger, superne subtiliter cinereo-pubescens, antennis articulo primo, secundo, dimidio basali tertii ipsaque basi quarti, apicibus femorum, tibiis tarsisque pallide flavis, ipso apice tarsorum ungviculisque nigris; articulo secundo antennarum margini laterali corii longitudine aequali, apice interdum obscuriore, fuscescente, tertio secundo fere $1 / 3$ et quarto $1 / 7$ breviore, tertio et quarto, basi excepta, fuscis; pronoto obsolete vel obsoletissime transversim subtiliter strigoso; corio margine laterali fortiter rotundato, cuneo brevi, fractura profunda, membrana fusca. Long. $f \mathrm{I}^{1} / 2-\mathrm{I}^{2} / 3 \mathrm{~mm}$.

Patria: insula Singapore, Vosung; 3 $\subsetneq$.

\section{Sthenaridea nov. gen.}

Generi Heterocordylus FiEB. affinis, sed primo aspectu gen. Sthenarus FIEB., ReUT. (divisionis Plagiognatharia) valde similis; 
ab illo structura capitis apicem versus sensim fortius declivis antennarumque nec non coxis anticis longioribus divergens, ab hoc areola alarum hamo destituta aroliisque ungviculorum magnis, liberis, apice conniventibus longe separanda; corpus ovatum, nitidulum, pilis squamiformibus metallicis hic illic adspersis; capite pronoto $1 / 3$ angustiore, nutante, a basi verticis ad apicem clypei sensim in arcum declivi, vertice margine postico arcuato-rotundato ipsum marginem apicalem pronoti tegente, tenuissime submarginato et utrimque ad oculum oblique impresso, clypeo in capite declivi, depresso, basi in linea intermedia oculorum posita a fronte obsoletissime discreta, loris discretis fortiter impressis, angulo faciali acutiusculo, genis humilibus, gula vix distingvenda; oculis magnis, minuscule granulatis, a latere visis oblongis et leviter subcompressis, etiam feminae in genas longe extensis, postice angulos anticos pronoti sub-tegentibus; rostro versus apicem sensim attenuato, apicem coxarum posticarum subsuperante, articulo primo dilatato medium xyphi subattingente; antennis dimidio corporis cum hemielytris longioribus, articulo primo apicem clypei haud superante, mox supra apicem oculorum interne inserto, duobus ultimis simul sumtis secundo sat multo longioribus; pronoto brevi, trapeziformi, lateribus rectis, callis parum discretis, strictura apicali sulcoque transversali destituto, basi tota truncata; scutello sat magno, basi detecto; hemielytris abdomen superantibus, cuneo breviusculo, fractura ejus profunda; membrana biareolata, areolis simul sumtis marginibus parallelis; xypho leviter concaviusculo, tenuiter marginato; orificiis metastethii obliquis, ovalibus; coxis anticis apicem mesosterni subattingentibus, tibiis subtiliter spinulosis, tarsis posticis articulis duobus ultimis longitudine subaequalibus, ungviculis mediocribus, apicem versus fortius curvatis.

Sth. pusilla n. sp.: nigricans vel fusco-nigra vel subsangvineo-nigra, sat nitida, subtiliter griseo-pubescens, superne et inferne hic illic pilis squamiformibus submaculatim parcius adspersis; articulo antennarum secundo, fere quarta parte basali excepta, rostro, apice femorum anticorum, tibiis tarsisque ochraceis, articulo secundo antennarum versus apicem ultimisque fuscis; tibiis concoloriter spinulosis, anticis punctis duobus fuscescentibus, inferiore in medio posito, posterioribus basi subsangvineo- 
piceis, posticis tota longitudine punctis minutis obsoletis fuscescentibus ad basin spinularum, tarsis articulo ultimo fusco; membrana fumata, macula parva ad apicem cunei aliaque majore ovata versus angulum interiorem basalem hyalinis; margine apicali mesoplerarum areisque orificiorum metastethii albidis; vertice (Q) oculo magis quam duplo latiore; antennis articulo secundo sublineari, margine postico pronoti circiter $1 / 3$ breviore; pronoto apice basi fere $1 / 3$ angustiore et longitudine fere duplo latiore. Long. ㅇ $2 \frac{1}{2} \mathrm{~mm}$.

Patria: Bengalia, 2 ใᄋ.

\section{Cyrtorrhinus (Fieb.) Reut.}

Hem. Gymn. Eur. III, p. 379.

C. lividipennis n. sp.: niger, vertice margine postico maculaque utrinque ad oculos cum hoc comfluente, insertionibus antennarum, ipso apice articuli earum primi, rostro, pronoto callis magnis, vitta media postica maculaque marginis basalis utrimque prope angulum posticum, scutello macula laterali magna triangulari, hemielytris totis, pectore medio, abdomine pedibusque totis pallide flaventibus vel lividis; vertice postice obtuse sed quam in C. Caricis Fall. distinctius marginato; capite basi pronoti fere $1 / 4$ angustiore; antennis articulo secundo margini basali pronoti longitudine aequali; pronoto lateribus fortius sinuatis; C. Caricis statura simillimus. Long. ${ }^{2} 2_{4}^{3} \mathrm{~mm}$.

Patria: Nicobar magna; 3 qQ

\section{Campylomma Reut.}

Hem. Gymn. I, p. 52 .

C. livida n. sp.: Pallide livida, capite medio testaceo, clypeo concolori, antennis articulo primo, basi et apice exceptis, extremaque basi secundi nigris; femoribus parce nigro-punctatis, posticis inferne punctis tribus magnis ante apicem in seriem obliquam positis nonnullisque majoribus marginis posterioris; tibiis spinulis nigris e punctis nigris nascentibus; vertice oculo paullo 
latiore; antennis articulo secundo latitudini capitis aeque longo et margine basali pronoti circiter $1 / 3$ breviore; vertice oculo paullulum latiore; C. Nicolasi Reut. et PUt. sat similis, corpore minore coloreque articuli primi antennarum mox distincta. Long. $\sigma^{7} 2^{1} / 3 \cdot \mathrm{mm}$.

Patria: Bengalia, I $\sigma^{7}$.

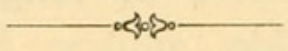

\section{ORCHESTES POPULI L.}

\section{GEFLETRAKTEN.}

I denna tidskrifts 3 :dje årgång sid. 30 omnämnes denna insekt såsom skadedjur. Denna sommar har den uppträdt så talrik i stadsträdgården i Gefle, att det fanns knappast ett enda blad på Populus balsamifera och nigra, som icke var angripet. Deremot var Populus tremula, som växte i samma parkanläggning, förskonad från det lilla skadedjurets angrepp.

Jacob Spångberg. 


\section{$2 \mathrm{BHL}$ Biodiversity Heritage Library}

Favrat, Louis. 1885. "Species Capsidarum quas legit expeditio danica Galateae descripsit." Entomologisk tidskrift 5, 195-200.

https://doi.org/10.5962/bhl.part.2238.

View This Item Online: https://www.biodiversitylibrary.org/item/45012

DOI: https://doi.org/10.5962/bhl.part.2238

Permalink: https://www.biodiversitylibrary.org/partpdf/2238

\section{Holding Institution}

Smithsonian Libraries

\section{Sponsored by}

Smithsonian

\section{Copyright \& Reuse}

Copyright Status: NOT_IN_COPYRIGHT

This document was created from content at the Biodiversity Heritage Library, the world's largest open access digital library for biodiversity literature and archives. Visit BHL at https://www.biodiversitylibrary.org. 